$$
\text { "bujdoso" — 2007/2/16 — 13:59 — page } 417 \text { — \#1 }
$$

\title{
New style in teaching word processing
}

\author{
MÁtyÁs ARATó and GYÖNGYi BujDOsó
}

Abstract. Teaching word processing is confined to looking through some menus and showing some functions of a word processor program, although technology presents just a small part of forming layouts. This fact causes that people who are writing documents spend a lot of time by trying to form, e.g., title pages or inner pages.

The present paper deals with a design of an online course on word processing that fits better the needs of many users. The online course is designed for teaching ( $\left.\mathrm{L}^{\mathrm{A}}\right) \mathrm{T}_{\mathrm{E}} \mathrm{X}$ by leading the students to the technical issues of the typesetting system through layout and grammar rules: demonstrates the most important basic recommendations of typography and grammar rules through samples, and shows how to program the currently displayed layout in the $(\mathrm{E}) \mathrm{T}_{\mathrm{E}} \mathrm{X}$ programming languages. This methodology suits better the common working habit, and can be a useful help in word processing documents.

Key words and phrases: teaching word processing, teaching ( $\left.\mathrm{L}^{\mathrm{A}}\right) \mathrm{T}_{\mathrm{E}} \mathrm{X}$, online learning course, typography and layouts in teaching informatics.

ZDM Subject Classification: B40, C30, U55, U58.

\section{Introduction}

Word processing is one of the most frequent activities performed by computer users. Anyone can use one or more programs for preparing documents. Most of them learn it in schools or read user guides on how to center and enlarge text for making headings, but sometimes - for example, when a title page is needed - they 


$$
\text { "bujdoso" — 2007/2/16 — 13:59 — page } 418 \text { — \#2 }
$$

need other information such as the size of letters or vertical spaces to be chosen above and below the headings. Another problem is that the default settings of the standard style sheets of all of the word processing softwares make the layouts uniform, and do not care about what the typographical traditions of the country in question recommend, because the localized versions of the softwares do not cover the localizations of the layouts of the style sheets.

Based on more than sixteen years of teaching word processing with the necessary recommendations of typography for students (whose specializations include mathematics, informatics, physics, foreign languages or philosophy), it is safe to say that, in general, their knowledge on this field is superficial, it is on a minimal level concerning layouts as well as capabilities of the applied word processor. When they have to prepare a document with special layouts, they have problems with the sizes of letters or margins to be chosen, etc.

Students who realize that more information is needed for preparing decorative layouts decide to learn word processing at courses, but only $20-30 \%$ of them has the possibility to join one ([5]). That is why we decided to put the complete material of the course onto the web making possible for students to learn about programs and typography or anybody else anywhere and anytime, that is to say helping people in life long learning.

In the present paper, after a survey of the state of the art of teaching word processing as well as the review of available books and online help on word processing, we present the main topics and focuses of the curriculum in brief, and draw the central goals and methodologies in designing the online course.

\section{Teaching word processing}

Considering the frequency of using word processors, the bibliography on teaching word processing is quite short when compared to teaching other fields of informatics. In addition, most of these articles deal with teaching word processing to disabled people or how to use word processors in teaching people with similar disadvantages (see, e.g., [15]) while other papers are on how to teach the functions of a word processor in classrooms (see, e.g., [9]).

\subsection{Teaching word processing in practice}

A common opinion concerning word processing is that anybody knows how to typeset texts. We can agree with it from a certain point of view because, after 


$$
\text { "bujdoso" — 2007/2/16 — 13:59 — page } 419 \text { — \#3 }
$$

all, everybody uses one or more tools for preparing documents, many of them read user guides or helps for learning, e.g., how to italicise a word or how to centering texts. Nevertheless only a few of them want to know more about the more complex and special capabilities and functions of word processing programs and the related typographical issues. That is why we should teach word processing as deriving from typography.

In teaching informatics the role of word processing in our daily life is not emphasized. The immediate regrettable assumption of this approach is that the knowledge on word processing is needless, and it is not important to pay attention on the layout of documents, although it has an essential role in our life during studies and later, as well ([5]).

\section{2. $\mathrm{T}_{\mathrm{E}} \mathrm{X}$ in teaching}

The term $\mathrm{T}_{\mathrm{EX}}$ distribution (or simply $\mathrm{T}_{\mathrm{EX}}$ ) denotes all of the softwares, tools, program languages, fonts and packages that belong to a highly controlled typesetting system which follow the ideas, principles and standards evolved by D. E. Knuth. That is, $\mathrm{T}_{\mathrm{E}} \mathrm{X}$ distributions contain program languages such as plain $\mathrm{T}_{\mathrm{E}}$, $\mathrm{L}_{\mathrm{E}} \mathrm{T}$, pdfTeX, pdftATEX, METAFONT, MetaPost, $\Omega$, their compilers and drivers, packages such as $\mathcal{A} \mathcal{M} \mathcal{S}$-TEX, XY-pic, skak (chess), diagram, and many tools such as converters. (AA) $\mathrm{T}_{\mathrm{E}} \mathrm{X}$ denotes the program languages of $\mathrm{T}_{\mathrm{E}} \mathrm{X}$.

$\mathrm{T}_{\mathrm{E}} \mathrm{X}$ is a well-designed typesetting system with many parts that can be used for typesetting documents made for various purposes. $\mathrm{T}_{\mathrm{E}} \mathrm{X}$ is free for noncommercial use and can be downloaded from any CTAN (see, e.g., [6]).

Because of these reasons, more and more teachers apply $\mathrm{T}_{\mathrm{EX}}$ in teaching various subjects: for example, MetaPost is good for teaching geometry (see, e.g., [11]), $\mathrm{T}_{\mathrm{E}} \mathrm{X}$ can be applied for preparing documents (textbooks, tests, etc.) for the purpose of teaching any subject (see, e.g., [12]).

\section{Books and online information on word processing}

There are some books on Hungarian typographical recommendations and many user manuals on word processors.

Books on typography contain general recommendations but only a few actual references to evaluation. It means that several arithmetic proportions can be found on adjusting margins (Gyurgyák's book [7] is a good example for that), but 


$$
\text { "bujdoso" — 2007/2/16 — 13:59 — page } 420 \text { — \#4 }
$$

there are no actual data on how much the size of the margins for a dissertation would be if it is to be printed onto A4 paper and bounded in paper. Virágvölgyi's book ([16]) which relates typography with certain functions of a typesetting program, can be taken as the only good example on connecting typography and word processor (or typesetting) programs.

Books and helps on word processors published in Hungarian deal with the functions of software, and do not contain typographical recommendations at all, generally. For example, it is well demonstrated how to underline words, but not mentioned that typographical traditions do not allow to underscore words at all in a normal typesetted text. The only exception is the new Hungarian $\mathrm{H}_{\mathrm{E}} \mathrm{X}$ manual [17]) which contains recommendations concerning how to form layouts.

There are some very good and useful online helps on using ( $\mathrm{IA}^{\mathrm{A}} \mathrm{T}_{\mathrm{E}} \mathrm{X}$ (see, e.g., the Polish Wirtualna TEX Akademia [8]) but these are based on program languages. Although, in the contents typographical terms can be found - such as headings, indentation -, in the section content there are no recommendations for, e.g., what size the indentation should be, but there is a source code on how to evaluate such a form. These user's guides do not contain typographical recommendations at all, and in many cases it is hard to find how to form something if the name of the command or environment is unknown for the user. The descriptions of additional packages of ( $\mathrm{AA}) \mathrm{T}_{\mathrm{E}} \mathrm{X}$ for inserting new forms or objects into a typesetted text (see, e.g., the skak [13] package for typesetting documents on chess) contain description on how to install and input the packages, and how to use the commands defined in them - without any recommendation for the layout of either the whole document or a small part the package.

In general, the problem of using (online) helps and (e-)books on word processing or typesetting programs is that they show the program's capabilities by its functions solely, that is, they demonstrate how to make a word in italics but do not say a word about where and in which cases it should be used. For example, it is well demonstrated how to underline words, though our typographical traditions do not allow to underscore words at all in a normal text.

In 1998 and 1999, during the evaluation of a project entitled MNEWS: a Network Information System (see, e.g., [1], [2]), authentic information on different subjects (among others on typography) had to be collected from the web regularly. The experience of this work was that just a few pages could be found on typography written in Hungarian, and these pages did not belong to authentic persons or companies. The conclusion was that it was almost impossible to find 


$$
\text { "bujdoso" — 2007/2/16 — 13:59 — page 421 — \#5 }
$$

authenticated information concerning Hungarian typographical recommendations on the world wide web.

\section{Methodology and technical aspects of the course}

The online course will reach its main goal if it enables the students to know the principal typographical recommendations, make them capable to determine correctly their needs, and to choose and use a proper tool for the given job. To achieve these objectives, the course should provide some possibilities for forming layouts of various kinds of documents showing - in parallel - the abilities and the (present) inadequacies of $\mathrm{T}_{\mathrm{E}} \mathrm{X}$.

\subsection{Curriculum of the course}

Here we specify, in brief, the focus points of the curriculum. (For more details see [3].) Our aim is to introduce all of these components into the online learning course. (This paper does not deal with those technical issues which concern the design of online learning frames.)

\subsubsection{Typographical recommendations}

The curriculum contains the recommendations of those issues of typography which are useful for students, teachers and many other people for preparing dissertations, booklets, questionnaires, formal letters, slides, curriculum vitae and broadsides, e.g., invitation cards. The main issues are the following: characteristics of letters (see samples of Figure 1), font types, methods of emphasis, shapes of paragraphs, shapes and captions of figures and tables, typesetting mathematical formulas, forms and roles of headings, forms of additional (generated) text such as table of contents or list of tables, shapes of various parts of pages (margins, headers, footers, page numbers, etc.), as well as the organization and the shapes

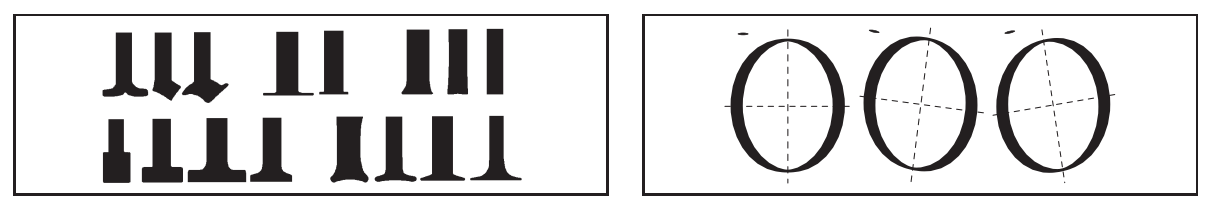

Figure 1. Some characteristics of letters: serifs ([14]) and optical axes ([4])
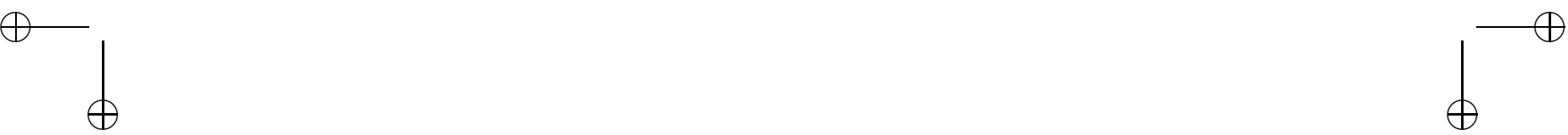


$$
\text { "bujdoso" — 2007/2/16 — 13:59 — page } 422 \text { — \#6 }
$$
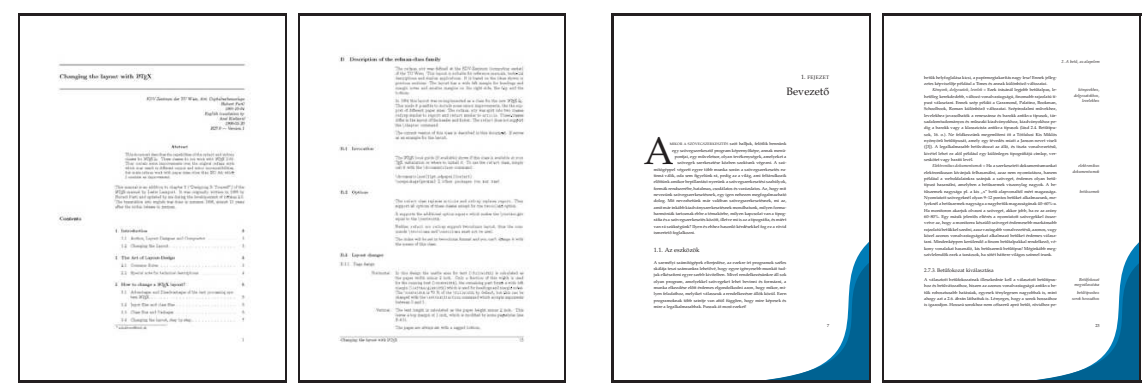

Figure 2. Sample pages from [10] and [4]

of various parts (title page, introduction, body, synthesis, conclusion, acknowledgements, bibliography, index, table of contents, appendix) of different kinds of documents under review.

For demonstrating various layouts, some scanned positive blueprints of books, journals, advertisements and other documents (see Figure 2) are presented. Showing negative samples are useful for preventing students from using well-known but rather ugly layouts. (Negative samples will be not presented on the web-avoiding legal consequences.)

\subsubsection{Grammar and special characters of our mother tongue}

A well-formed text needs more attention on grammar. Students have to understand that typo and grammatical errors have stronger interfering effects in well formed texts. Unfortunately, most of the new books, journals and web pages on computer science make a number of such errors. The curriculum deals with the allowed forms of dates, the conjugation rules of foreign words, acronyms and initial words as well as the shapes and use of special characters (e.g., punctuation marks, quotes, (round and square) brackets, hyphen, n-dash, m-dash, minus sign, non-breaking space) of our mother tongue and some other languages.

\subsubsection{Tools: program languages and softwares}

Students have to get to know the special supports, abilities and insufficiencies of the applied programs, i.e., an integrated environment and the ( $\left.\mathrm{LA}_{\mathrm{A}}\right) \mathrm{T}_{\mathrm{E}} \mathrm{X}$ program language(s). For each issue of typography there are web pages that inform the students if the selected layout can be solved easily or not by $\mathrm{T}_{\mathrm{E}} \mathrm{X}$ and draw their 


$$
\text { "bujdoso" — 2007/2/16 — 13:59 — page } 423 \text { — \#7 }
$$

attention to the automatisms of special items (e.g., headers, footers, numbering and positioning figures).

\subsection{Main concepts of the online course concerning the curriculum}

The content of the online course has to show good samples for different kinds of documents, demonstrate recommendations on how to form layouts, suggest formats for emphasizing special parts of texts (e.g., lists, citations) and some ways of organization of information in lengthy documents, inform the students about those forms which are not allowed or recommended by our typographical traditions.

The online course must emulate the common working habit: users select a part of a sample document then the related typographical recommendations and grammatical rules as well as the ( $\mathrm{L}) \mathrm{T}_{\mathrm{E}} \mathrm{X}$ source code of the selected part.

\subsection{Organization of information}

Certain different learning styles have to be supported. Learners should have the possibility to choose from three ways:

- selecting a sample document and choosing a part of it for looking up the related typographical recommendations, grammatical rules or ( $\left.\mathrm{LA}_{4}\right) \mathrm{T}_{\mathrm{E}} \mathrm{X}$ source code;

- taking a survey of the typographical and grammatical issues as well as the topics of (LA) $\mathrm{T}_{\mathrm{E}} \mathrm{X}$ step-by-step;

- choosing a (LA)TEX command (environment, etc.) and going to the sample document which shows the typical use of the command.

A common way for using hypertexts has to be applied, i.e. the related blueprints, topics and the definitions of important notions and terms, etc. must be linked.

\subsection{Exercises}

We plan to apply two kinds of exercises in the system:

- Students can reproduce sample pages that contain a number of exercises. In this case the result has to have exactly the same layout as the sample page does. 


$$
\text { "bujdoso" — 2007/2/16 — 13:59 — page } 424 \text { — \#8 }
$$

- Students have possibility to choose a document type to be designed and effectuated by using $\mathrm{T}_{\mathrm{E}} \mathrm{X}$ applying the typographical recommendations and grammatical rules.

In both cases the source code has to consist of appropriate commands and has to be clear. During the work students can ask for help or preliminary assessment from the teacher.

Because $\mathrm{T}_{\mathrm{EX}} \mathrm{X}$ has some colourful program languages and students can solve problems in their own ways, checking the correctness of the source code cannot be automated, it has to be the teacher's responsibility, who should help, sometimes guide the students in their work to find an appropriate way leading to a good solution.

\subsection{Assessments}

Assessments should be performed in accepted ways. During a semester formative assessments have to be performed to help the students' work.

Students can ask questions in e-mails sent to the teacher or to other students, using an e-mail list. Most of the questions will refer to problems resulting in compilation errors.

The tests for self-assessment should contain questions concerning the evaluation of special layouts, the theory of low level mechanisms of the programs as well as how to write or modify macros and style files. The answers for these questions show well the depth of students' understanding concerning the problems and programs.

Self-marking tests has to be used as well. Tests should contain questions on the most important parts of typography and the grammatical relevancies as well as on ( $\mathrm{LA}) \mathrm{TEX}$.

\section{Conclusions and perspectives}

The general method of teaching word processing is teaching the functions of a software. Whereas word processing plays an important role in the daily life of every computer user, this methodology has to be transformed into a typography centered concept.

Developing an online course on word processing based on typography and $\mathrm{T}_{\mathrm{E}} \mathrm{X}$ is an up-to-date task. It would help teachers who teach informatics, mathematics or any other subject in secondary schools or in higher education to apply 


$$
\text { "bujdoso" — 2007/2/16 — 13:59 — page } 425 \text { — \#9 }
$$

typographical viewpoints when teaching word processing, to use $\mathrm{T}_{\mathrm{E}} \mathrm{X}$ in education, and to prepare various types of documents in their work with $\mathrm{T}_{\mathrm{E}} \mathrm{X}$. The possibilities of displaying and copying source codes would be a big help to those people who use $\mathrm{T}_{\mathrm{E}} \mathrm{X}$ but are not familiar with $\mathrm{T}_{\mathrm{E}} \mathrm{X}$ programming.

Consequently, such an online system can function as a curriculum for a course in secondary or higher education as well as a manual and online database during word processing for anybody, i.e., it can be a good tool for life long learning.

Giving a free access to the online course would help everybody who tries to find information for typographical recommendations on the web, independently of the word processor applied.

\section{Acknowledgements}

The author is grateful to Professor Katalin Bognár and Professor Mátyás Arató for their valuable suggestions.

\section{References}

[1] Károly Bósa, Gyöngyi Bujdosó, Ádám Bujnóczki, Attila Kuki, Gábor Kusper, and Szabolcs Márien, User manual for the MNEWS system, Lajos Kossuth University and OMFB, Debrecen, 1999, (in Hungarian).

[2] Gyöngyi Bujdosó, Relationships among world wide web, typesetting methodology and typography, Analele Universităţii din Oradea (2001), 93-98.

[3] Gyöngyi Bujdosó, Online learning course on wordprocessing based on typography, Analele Universităţii din Oradea (2005), 33-36.

[4] Gyöngyi Bujdosó, Some recommendations on word processing texts, Textbook, University of Debrecen, Debrecen, 2005, (in Hungarian).

[5] Gyöngyi Bujdosó, Students should learn to use word-processors, 2006, (submitted).

[6] CTAN: Comprehensive $T_{E} X$ Archive Network, http://www.ctan.org.

[7] János Gyurgyák, Manual for editors and authors, Osiris Publishing House, Budapest, 1996, (in Hungarian).

[8] W. Macewicz and S. Wawrykiewicz, Wirtualna TEX akademia, 2004, http://www. ia.pw.edu.pl/ wujek/tex/, (in Polish).

[9] Amiram Raban, Word processing learning techniques and user learning preferences, SIGCHI Bulletin 20 (1988), 83-87.

[10] babalayout_e - a sample document of the refman package, 2003, CTAN/packages/ tex/latex/refman. 


$$
\text { "bujdoso" — 2007/2/16 — 13:59 — page } 426 \text { — \#10 }
$$

[11] Denis Roegel, La géométrie dans l'espace avec metapost, Cahiers GUTenberg 39-40 (2001), 107-138.

[12] Jean-Michel Sarlat and Jean-Paul Vignault, $T_{E} X$ dans l'enseignement secondaire, une expérience, Cahiers GUTenberg 39-40 (2001), 63-69.

[13] The skak package, Downloadable from TEX Catalogue: http://www.tug.org/ tex-archive/help/Catalogue/.

[14] Andrzej Tomaszewski, Leksykon pism drukarskich, Varsó, 1996.

[15] J. K. Torgesen and T. A. Barker, Computers as aids in the prevention and remediation of reading disabilities, Learning Disability Quarterly 18 (1995), 76-87.

[16] Péter Virágvölgyi, Using typography - by computers, Osiris Publishing House, Budapest, 2002, (in Hungarian).

[17] Ferenc Wettl, Gyula Mayer and Péter Szabó, ${ }^{A} T_{E} X$ manual, Panem, Budapest, 2005, (in Hungarian).

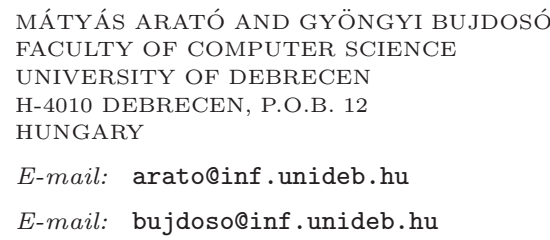

(Received June, 2006) 